\title{
La razón económica capitalista y la teología política neoconservadora*
}

\author{
José María Mardones, \\ Instituto de Filosofia CSIC, Madrid. \\ Centro de Reflexión Teológica, San Salvador.
}

El término neoconservador se aplica en el mundo político-social a una serie de intelectuales norteamericanos de renombre intemacional. Señala una "tendencia" más que un "movimiento". Agnupa, entre los más representativos, a sociólogos, politólogos y publicistas tan conocidos como D. Bell, P. Berger, I. Kristol, D P. Moynihan, N. Glazer, M. Novak, N. Podhoretz, S. Martin Lipset, R. J. Neuhaus, etc. Su interés estriba en el alcance de sus pretensiones: con ellos nos sumergimos en un diagnóstico de nuestro tiempo, sobre todo de la denominada crisis de las sociedades burguesas del capitalismo, y en un enérgico intento de recrear un nuevo consenso sociopolílico en la sociedad norteamericana. Hay, por tanto, un proyeclo de legitimación de un modo de concebir la interrelación entre la economía, la política y la cultura que denominarán capitalismo democrático.

Llama la atención la importancia que en su diagnóstico y propuestas de solución tiene la religión. Hay un auténtico uso de la religión -de la tradición judeo-cristiana, como gustan decir- para legitimar el capitalismo democrático y para compensar las contradicciones del sistema. El que sus propuestas hayan obtenido un eco intemacional ${ }^{2}$ hace del neo-conservatismo norteamericano un fenómeno sociopolítico y culural digno de atención. Su enfrentamiento con la teología de la liberación (Novak, Berger, Neuhaus) forma parte de la lucha cultural por recrear un nuevo counter-establishment propicio al capitalismo democrático.

En este artículo me voy a centrar en el comentario a la legitimación religiosa

- Este artículo forma parte de un ensayo que con el título Capisalismo y religión. La religión polírica neo-conservadora aparecerá en breve en Sal Terrae, Santander. 
que efectúan del capitalismo a través de su referencia al subsistema económico y sus logtos. Una buena perspectiva para percibir la sensibilidad necoconservadora y su manipulación de la religión cristiana.

\section{La devoción neo-conservadora por el capitalismo}

El capitalismo democrálico es presentado como el sistema social más propio para la liberación. Esta tesis central de M. Novak ${ }^{3}$, participada, con algo menos de intensidad retórica, por sus colegas teológicos neo-conservadores R. J. Neuhaus y R. Benne (luteranos) y por los sociólogos y politólogos P. Berger, D. Bell, S. Lipsel, N. Glazer, I. Kristol, S. Huntington, expresa la devoción, neoconservadora hacia el capitalismo democtático.

\subsection{Las aportaciones históricas del capitalismo}

Los autores neo-conservadores citan con gusto "el himno casi hiperbolico a la burguesia" (D. Bell) creadora de la revolución capicalistat de El Manifiesio del partido comunista: "durante su dominación de apenas cien afios, la burguesía ha creado fuerzas productivas más masivas que todas las generaciones anteriores". Pero Marx y Engels veían, junto a "esta revolución constante de los instrumenlos de producción" y de las relaciones sociales que disolvían en el aire no sólo anticuadas y opresoras relaciones, sino, incluso, elementos positivos de la tradición y la vida humana. Sin embargo, Novak, y de modo semejante $P$. Berger, entonan un canto que ve, casi exclusivamente, las aportaciones del capitalismo. "De todos los sistemas de economía política que ha plasmado nuestra hisloria, ninguno revolucionó tanto las expectativas ordinarias sobre la vida humana -en cuanto a prolongar el lapso de vida, tomar concebible la eliminación de la pobreza y del hambre, ampliar la gama de altemativas humanascomo el capitalismo democráticons. P. Berger resumirá sus ideas diciendo que "el capitalismo industrial avanzado ha generado, y continúa generando, el más alto nivel de vida material para grandes masas de gente de la historia de la humanidad" . Novak no tendrá empacho en asumir como logros exclusivos del capilalismo todos los éxilos que desde 1800 se han efectuado en el mundo occidental en lo referente a la lucha contra la pobreza, el analfabetismo, la enfermedad, la mortalidad, etc., o las novedades positivas de la comunicación e interdependencia internacionales. Incluso recuerda, al contraluz de la denuncia del papa Juan Pablo II sobre la existencia aún de 800 millones de hambrientos en este planeta, la existencia de 4,000 millones de no hambrientos, como una realización capitalista ${ }^{7}$.

Vista e interpretada la historia de la sociedad modema de este modo, no le cabe la menor duda acerca de la capacidad liberadora ejercitada históricamente por el capitalismo.

Pero, ¿qué es el capisalismo para los neo-conservadores? 


\subsection{El capitalismo democratico y sus principios fundamentales}

"Capitalismo", acepta P. Berger, tanto en su uso cariente como científico, dice relación "a un conjunto de disposiciones económicas". Pero, aclarará enseguida, "el ciudadano corriente de una sociedad 'capitalista' encuentra las disposiciones economicas como formando parte integrante de 'mundos' sociales mucho más amplios"'. Con todo, terminará, con Weber, haciendo hincapié en lo que la mayoria de la gente piensa al emplear este término: la producción para un mercado, por individuos o grupos de individuos emprendedores, a fin de obtener un beneficio"

Novak insistirá en las implicaciones de lo económico con otros elementos que no tienen nada que ver con la economía. Desde su optica, el capitalismo está estrechamente imbricado con otros elementos políticos y culturales, formando un todo único que llamará capitalismo democrótico. Entenderá por tal un sistema social con "tres sistemas dinámicos y convergentes que funcionan como uno: un sistema democrático, un sistema económico basado en los mercados e incentivos, y un sistema moral cultural pluralista y, en el más amplio sentido de la palabra, liberal"10. Es decir, se está refiriendo a un modo de estructurar la sociedad de la que es ejemplo máximo hoy Estados Unidos. Aunque aceptan que la Europa democrática caeŕa bajo la misma denominación, sin embargo, verán el auténtico canon en la realización estadounidense y no en la europea. Las proclividades europeas hacia el socialismo democrático les hacen ver ahí a los nco-conservadores un enemigo camuflado que se orienta sutilmente hacia el colectivismo.

Nos damos cuenta ya de una serie de énfasis a los que van a ser muy sensibles los neo-conservadores.

- El capitalismo, en cuanto sistema de producción basado en el mercado, la propiedad privada de los medios de producción y la libre empresa individual con el propósito de obtener beneficio ${ }^{11}$.

- La autonomía individual y su potenciación mediante la creatividad competiliva, que hace sospechosa loda ingerencia estatal o énfasis en las actividades e instituciones públicas ${ }^{\prime 2}$.

- La política cultural que propicie los valores y motivaciones de una sociedad que favorezca el desarrollo capitalista (ética puritana, innovación racional, teología de la creación,.... $)^{13}$.

Se terminará diciéndonos que sólo un sistema social que garantice estos aspectos puede asegurar. eficiencia económica para luchar contra la pobreza y promover la justicia; descentralización que haga la democracia necesaria y evite los peligros de la concentración de poder, fundamentación ético-religiosa para dar sentido y sostener las necesarias renuncias, la capacidad de compartir y sacrificarse, que haga posible una sociedad solidaria y justa ${ }^{14}$. 


\section{Las virtudes del capitalismo}

El capialismo, dicen, es el mejor sistema económico y el que favorece la mejor estructuración social, porque es el que promueve la mayor producción de bienes (eficiencia y crecimiento), su distribución menos desigual y la menor coerción de las autoridades sobre las personas y las ideas de los ciudadanos (libertad y pluralismo) ${ }^{15}$. La eficiencia y crecimiento que proporciona el capitalismo están vinculados, como hacen notar repetidamente los neo-conservadores, a las enormes ventajas de la economía de mercado. El sistema competitivo de mercado es el que proporciona las condiciones y el estímulo para una revolución constante de los medios de producción, porque desata la creatividad y la invención. Schumpeter, nos recordarán estos autores, ya percibió esta cualidad del capitalismo avalada históricamente por sus logros. La denominó "destrucción creativa"16. Consiste en la continua sustitución de la producción y de los mélodos menos eficientes por los más eficientes.

Efíciencia y crecimiento están enraizados, como vemos en una serie de virudes que Novak pone en el corazón del espiritu capitalista: la creatividad humana y el espíritu de empresa ${ }^{17}$. Sin fantasia creadora no hay inventiva ni crecimiento eficaz. Y junto a la imaginación creativa está el trabajo en equipo y la coordinación racional y humana que conlleva la gestión empresarial. Contra la crílica weberiana de la unilateralidad de la racionalidad económico-capitalista, Novak ofrece una visión más compleja para hacer justicia a otras dimensiones de la razón humana's.

La economía de mercado al propugnar la separación de poderes permite también - y no sólo porque a través del crecimiento favorece el bienestar y con él la libertad- el ejercicio de la democracia Permite la distinción entre poder económico y poder político ${ }^{19}$. Corno dirá Berger con su pretendida punta de contrastación empírica y, por tanto, de afirmaciones cuidadosas de ser falsadas, "el capitalismo es una condición necesaria, aunque no suficiente. de la democracia $a^{20}$. Pero se constata que "todas las democracias son capitalistas; no hay democracias en el socialismo real; y muchas sociedades capitalistas no son democráticas"21. Hay que aceptar, al menos, que la economía de mercado favorece la descentralización y con ella la dispersión del poder y la toma de decisiones más democrálicas, aunque nunca se está a salvo de la tiranía política o económica. Los neo-conservadores no son tan ingenuos como para garanlizar a través del capitalismo la ausencia de comupción o de injuslicias ${ }^{22}$.

Ahora bien, las virtudes anteriores de la economía de mercado conducen a crear las condiciones que favorecen la libertad y la justicia Posibilitan un pluralismo social y con él el ejercicio de la libertad y solidaridad. La potenciación de las estructuras y grupos intermedios (visto en América desde Tocqueville) es una potenciación de la dimensión solidaria y comunitaria del capitalismo democrático. 
Contra la acusación de favorecer el individualismo y los intereses de grupo la lógica del capitalismo democrático tiende, más bien, a favorecer lo contrario ${ }^{23}$.

El clímax de esta espiral de virtudes del capitalismo es presentada a través de sus capacidades distribulivas. La economía de mercado distribuye mejor que cualquier otro sistema. Por supuesto mejor que la planificación estatal e, incluso, mejor que a través de ciertas medidas de la lucha contra la pobreza del Estado de bienestar. Berger se esfuerza en mostrar cómo esta capacidad distributiva del capitalismo está fundada en análisis empíricos contrastables. La llamada curva de Kuznets" viene a decir que "si el crecimiento económico perdura en el tiempo, las desigualdades en la riqueza y los beneficios se agudizan al comienzo, después disminuyen rápidamente para posteriormente alcanzar una meseta relativamente estable". La experiencia del capitalismo asiático no sólo confirma la tesis de Kuznets, sino que muestra que no es necesario incrementar las desigualdades al comienzo para alcanzar una distribución menos desigual con el crecimiento económico's. En suma, el capilalismo mejora el destino de todos. Ricos y pobres por igual oblienen más con el capitalismo.

Un sisterna económico y social con estas virtualidades no cabe duda que será el más liberador, dentro de la ambiguledad en que inevitablemente están presos todos los sistemas sociales. Es la consecuencia que no se hace esperar y que van a sacar los neo-conservadores.

\subsection{Las posibilidades liberadoras del capitalismo}

La revolución capitalista, afíman, es el proceso económico-político más liberador que ha existido. No hace falta más que analizar los datos con objelividad para convencerse de ello, nos dirán de una u otra manera nuestros autores. Es una liberación económica y política, una liberación de la miseria y la tirania ${ }^{2 x}$.

Esta liberación tiene un lugar donde se ha contrastado con éxito: Norteamérica. Por eso, su símbolo (como lo fue para los abuelos de M. Novak) es la estatua de la libertad ${ }^{27}$. Sus liberaciones no están escrilas en libros, ni siquiera en teología, sino "enterradas en instiluciones, práclicas y hábitos; existe mucho más potentemente en la realidad que en los libros" ${ }^{\prime 2}$.

Participa, con la teología de la liberación latinoamericana, de su "opción por el pobre" 29 , de la lucha por la justicia ${ }^{30}$ y del cambio estructura ${ }^{31}$. Pero avanza más allá de los deseos: trata de realizar prácticamente esta opción. De ahí que el primado descanse sobre la asistencia práctica al pobre. Desde este punto de vista hay radicales diferencias, dicen, entre "la teología de la liberación norteamericana" y la teología de la libcración latinoamericana. Mientras ésta es exhortativa y desiderativa y se mueve en el campo ideológico (teológico y político-ideológico), la teología de la liberación neo-conservadora discute más los 
problemas económicos que los teológicos ${ }^{32}$. Es decir, la liberación que quiere producir la teorización neo-conservadora es práctica, real, y por ello centra su interés en la economía política Es una liberación que se puede someter al test empírico" ${ }^{33}$. La teología de la liberación latincamericana, por el contrario, es utópica, y, por tanto, pre-leórica. Dicho de otro modo, no es todavía política, sino meramente exhortativa ${ }^{34}$.

No tiene nada de extrafio que Novak, Berger et alii recomienden insistentemente "la revolución capitalista" como el mejor camino de liberación para el tercer mundo y, especialmente, para América Latina ${ }^{35}$. Novak dira, con el convencimiento de los que exportan el mejor producto, que "la teología de la liberación dice que América Lalina es capitalista y necesila una revolución. Su sistema actual es mercantilista y cuasi-feudal no capitalista y la revolución que necesita es liberal y católica"36.

El fallo fundamental del tercer mundo, ejemplificado vivamente en América Latina, es el de no ser sociedades capilalistas. Si lo fueran de verdad habrían alcanzado la liberación. La estructuración econónico-política capitalista es quien trae la liberación real a las sociedades.

Esta pretendida legitimación por los hechos de la capacidad liberadora del capitalismo democrático se encuentra, sin embargo, con el muro de la incomprensión. ¿A qué se deben, tras tanto éxito liberador, las reticencias, cuando no el franco rechazo, que suscila el capilalismo?

\section{La mala prensa del capitalismo}

El sentimiento anticapitalista, reconocen, estra ampliamente extendido. Ha penetrado profundamente entre los intelectuales, sobre todo, los representantes de las ciencias humanas, y mass-media ${ }^{37}$, e, incluso entre teólogos y obispos [Novak recoge la opinión de López Trujillo al respecto: "el capilalismo es un fallo humano" ${ }^{138}$ ], aunque a juicio de otros neo-conservadores estariamos ante un creciente atractivo del capitalismo ${ }^{39}$. La razón que encuentran los neo-conservadores para esta desafección intelectual es varia y se enraíza en el atractivo que la utopia socialista provoca con su capacidad mítica ${ }^{40}$, procedente de la tradición gnóstico-apocalíptica ${ }^{1}$, a la que son proclives los intelectuales y su espiritu de oposición o de "cultura adversaria" (L. Trilling). Pero estaría generada también por el espíritu sobrio del sistema mismo: el capitalismo no tiene capacidad mítico-política ${ }^{42}$, genera una forma de vida poco romántica e insulsa, "la existencia burguesa", y, por lo tanto, no satisface el anhelo espiritual de algo más grande, heroico y exaltado que el mejoramiento de las condiciones de $v^{v i d a}{ }^{43}$. De esta forma, como ya vio Schumpeter, el capitalismo en la medida en que genera más y más prosperidad y mejores condiciones de vida, produce y subsidia más y más a sus propios críticos. 
De aquí se deduce la necesidad para los neo-conservadores de un esfuerzo ideológico y publicitario a fin de dar a conocer los logros y virtualidades del capitalismo. Llevado al terreno teológico se traducirá en un intento para "hacer una tcologia de la sociedad liberal ${ }^{\mathbf{m 4}}$, o mejor aún, una teología de la liberación norteamericana, que será, como ya propuso ese autor hace afos, un intento para mostrar los presupuestos teológicos"s de "una teología del capitalismo democrático" ${ }^{\text {"ar. }}$.

\section{La afinidad judeo cristiano-capilalista}

El concepto weberiano de afinidad ${ }^{47}$ está muy presente en el tratamiento religioso neo-conservador del capilalismo. Se puede afirmar que es la hipotesis que sintetiza su esfuerzo para sanear el sistema del capitalismo democrático mediante la recuperación de la tradición judeo-cristiana y la écica puritana Hay una familiaridad, afirman, entre el sistema económico capitalista de libre mercado, el sistema político democrático y la religión cristiana. Sobre esta afinidad va a trabajar masivamente $M$. Novak. No se trata de "cristianizar el sistema", sino de mostrar la congruencia interna entre el capitalismo democrático y el cristianismo ${ }^{40}$. Accedamos, siguiendo su esfuerzo, al modo como comprenden los neo-conservadores las relaciones religión-sociedad, concretamente, con el capitalismo democrático.

\subsection{El carácter social de la religión}

Frente a las tesis privatizantes de la teoría de la secularización que reduce la existencia y las funciones de la religión en la sociedad modema a la esfera privada (individuo, familia), los neo-conservadores reivindican su función social. Ciertamente, no será la de legitimar directamente las actividades políticoeconómicas. Pero si que toman en cuenta: (a) la presencia institucional de la religión a través de las iglesias, las sinagogas, las universidades, los periódicos, los editoriales, los canales de televisión, las asociaciones de intelectuales... que no se limila a la privacidad de la conciencia moral ${ }^{49}$; (b) el influjo que ejerce (y debe ejercer) la religión a través de la configuración del ethos social, que nunca será, matiza Novak, el de dirigir el sistema, sino de influir directamente "inspirando a millones de individuos y compitiendo con ideas y símbolos ajenos en un mercado pluralista"so.

Ahora bien, ¿qué puede hacer la religión en una sociedad pluralista y democrálica, a qué se reduce su pretendida influencia? Novak aborda una desasosegante pregunta para los teólogos políticos y para sociólogos de la religión en las sociedades secularizadas de occidente ${ }^{\text {st }}$. Sus propuestas son esperanzadoras, supuesto que "la filosofía subyacente en el pluralismo es congruente con la comprensión judaica y cristiana de la vida humana, que incluye una visión de la historia, del pecado y de la comunidad ${ }^{\mathbf{m 2}}$. 


\subsection{Las raíces evangélicas del capitalismo}

La tesis de la afunidad entre el capitalismo de mercado, la democracia y la tradición judeo-cristiana tiene una expresión fuerte en Novak: le permite hablar de "ráces evangélicas del capitalismo" ${ }^{3}$. "Como la democracia, el capitalismo brotó de un suelo especílicamente judeo-cristiano. Sus pre-juicios son también judeo-cristianos. Su ética es, en alguna medida, sulancialmente - pero no del todo- judeo-cristiana"s4. Especificando estas afirmaciones rotundas:

(a) El carácter social del capitalismo ofrece afinidad con el carácter social del reino de Dios y la preocupación cristiana por el bien, por la salvación de todos. Contra un difundido prejuicio, el capitalismo no es individualista. Como se ve en A. Smith su objetivo no es la riqueza de los individuos, ni la riqueza de Gran Bretaña, sino la riqueza de las naciones, de todas las naciones sin excepción"ss. De aqul que Novak acentúe la "ética de la organización" como constiutiva del capitalismo y la producción de un "individuo comunitario". Lo que otros pensadores juzgan que ha sido fruto del socialismo y su confronlación con el capitalismo, al que ha conseguido humanizar, Novak lo atribuye a la ética del capitalismo: el surgimiento de sindicatos, la administración colectiva, el reparto de utilidades, los plazos de pensión, etc.. ${ }^{\text {st }}$.

(b) El mercado como promotor de libertad e interdependencia ofrece familiaridad profunda con la tradición judeo-cristiana promotora de hombres libres que ejerciten actos libres de la conciencia personal.

De nuevo serán A. Smith y Madison los hombres en los que ve Novak la clave explicativa de un sistema económico basado en el libre mercado y en los incentivos personales. No requiere para su funcionamiento la resolución previa de las diferencias ideológicas, teológicas o filosóficas. Deja a cada persona en libertad, con lo cual "refuerza el ideal de la integridad personal en todas las esferas"s7. Esta actitud abierta favorece el pluralismo y la tolerancia. Y "revelará abundantemente la existencia del pecado", es decir, del mal uso de la libertad. Pero lejos de imposiciones ideológicas totalitarias, trabajará con realismo para proteger sus libertades económicas. Esta "indiferencia ideológica" hace de las actividades económicas un elemento de conjunción e interdependencia entre los hombres. Sin olvidar que la libertad en la esfera económica "complemente la de la esfera moral-cultural que defiende la conciencia de cada persona, y la de la esfera política que defiende los derechos humanos de todas las personas"ss.

(c) La concepción abierta de la historia humana, según el espíritu del capitalismo, es afin a la concepción abierta y entregada a la responsabilidad libre del hombre de la tradición judeo-cristiana ${ }^{39}$.

A esta afinidad que impulsa la creatividad capitalista y la responsabilidad cristiana, la denomina Novak con el teólogo B. Lonergan "probabilidad emergente"60. Supone la puesta en marcha de todas nuestras capacidades y la bús- 
queda de las mediaciones adecuadas para alcanzar los objetivos propuestos. De aquí que el talante que la impulsa es realista, sobrio, "meliorista" y poco dado a entusiasmos gnóstico-mesiánicos. Su gran enemigo será, precisamente, la inflación verbal utópica, tal como la ven los neo-conservadores encamada hoy, en el socialismo aun democrático ${ }^{61}$.

(d) La vigilancio permanente frense a la concepción de la libertad ofrece afinidad con la concepción judeo-cristiana del pecado ${ }^{62}$.

El capilalismo, como la democracia, está basada sobre la concepción de la radical ambigledad y capacidad destructiva de la voluntad humana De aqul que trate de vigilar y proteger su libertad. Para ello debe atender, y esta es una preocupación constante neo-conservadora, los peligros de "la tirania, principalmente la del Estado, pero también la del poder particular desmesurado"d. No aspira a eliminar el pecado $0^{\text {t4 }}$, sino a disminuir las consecuencias indeseadas favorecer la liberad y evitar la tiranía, frente a la estrategia económico-politica socialista de evitar las desigualdades, o, la tradicional, de evitar el desorden.

Al final, inspirado en Maritain, Novak reiterará su hipotesis: el capitalismo como la democracia, tiene ralces biblicas. Y este recordatorio es tanto más importante cuando más olvidada y amenazada está dicha afinidad. Asistimos, opinan estos autores neo-conservadores, a una auténtica reacción de la "culuura adversaria" de la "nueva clase" intelectual contra el capitalismo. Y esto ocurre también dentro de las iglesias ${ }^{66}$. Por esta razón, la tesis de la afinidad tiene una intención política clara: oponerse a las tendencias izquierdistas. Novak dira que su esfuerzo por construir una nueva teología de la ciencia económica capitalista "servirla a un alto fin" si "no hiciera más que promover la elucidación crítica y destronar los usos ideológicos del lenguaje religioso"s.7. Entre estos se hallan dos tipos de toologia a los que Novak ataca con acrime panfletaria: la teologia política contemporánea de J. Moltonann y J. B. Metz, y la teología latinoamericana de la liberación ${ }^{68}$. Su propuesta, utilizando la experiencia de Niebuhr, el teólogo socialista americano defraudado al final de su vida, sera la del capitalismo democrático ${ }^{69}$.

Vamos a indicar brevemente los rasgos más importantes de esta teologla del capicalismo democrático. Accedemos al último peldaño de su justificación por la via sactalizadora.

\section{Teología del capitalismo democrático}

Dos han sido las vías utilizadas por M. Novak para esbozar la teología del capitalismo: (a) la traducción en calegorlas económico-capitalistas de las reverberaciones de los dogmas centrales del cristianismo y (b) las principales ideas biblicas que parecen inspirar el nuevo sistema socio-económico del capitalismo americano. Dos métodos que, quizá, se pueden considerar complementarios, 
pero que, dado el grosero concordismo que recorre el primer intento, parece como si el autor quisiera inclinarse en sus últimas publicaciones por el segundo.

\section{1. "Una teología del capitalismo democrático"}

Así titula Novak el último capítulo de su libro El espíritu del capitalismo

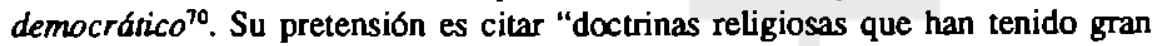
poder para llevar a la comunidad, lenta y azarosamente, como una fuerza real, el desarollo económico, la libertad política y la adhesión moral-cultural al progreso". Seguirá la versión cristiana de seis doctrinas que han impulsado en la historia el surgimiento del capilalismo democrático.

\section{(a) La trinidad}

Novak destaca la comunidad en el concepto cristiano de Dios. Después se lanza a una desaforada analogía con varios aspectos del capitalismo democrático, especialmente, la erección de una comunidad humana sin dañar la individualidad. Para ello, la separación y autonomización de los diversos ámbitos político, económico, legal, es fundamental, como, también, las estructuras intermedias entre Estado e individuo.

\section{(b) La encarnación}

El Dios cristiano se aviene a descender e ingresar en la historia humana como un hombre cualquiera. Respetó, por tanto, la historia y sus limitaciones. De aquí salta Novak a una "espiritualidad" del realismo capitalista. Critica el evasionismo utópico socialista y propugna "el respeto al mundo tal cual es", en su ambiguiedad radical que no permitirá nunca realizar aquí el reino. El paso al mundo económico político de la doctrina de la encarnación sirve para exaltar la simplicidad y practicidad de "la revolución americana" y de la economía de la búsqueda del interés propio rectamente entendido ${ }^{71}$.

\section{(c) La competitividad}

Novak saca del ejercicio responsable de la libertad humana cabe Dios motivo para presentar la vida cristiana como una lucha competitiva. No sólo un esfuerzo y una lucha, sino una lucha competitiva. Así se entiende la desigualdad constiutiva de los seres humanos. Las analogías tras un mohin de disgusto con un capitalismo atravesado por la búsqueda del éxito material cimentado en las "virtudes puritanas", llegan hasta equipararlo con "la búsqueda conjunta" (competere) de la salvación cristiana. El medio dinero es un elemento neutro, "inocente en sí mismo", de esta carrera tras el éxito que, realizada dentro del sistema americano, se transforma en el tocquevilliano "interés propio bien entendido", y, por consiguiente, en interés público. Estamos lejos del equivocado y tendencioso juicio —dirá Novak- que supone que "el espíritu competitivo por 
el dinero es el peligro espiritual más mortal para la humanidad".

\section{(d) El pecado original}

Es un leit-motiv de Novak la afinidad de la concepción cristiana del pecado y el capitalismo. Se funda así una concepción pesimista, "una reservada fe", de la naturaleza humana, dafiada en su libertad y perturbada en sus pasiones. La economía política capitalista funciona con esta "teoría del pecado". De aqui que "combata la tiranía, fragmente y controle el poder, pero no combata el pecado". Es tolerante - por mor de la libertad- con el vicio, pero busca, en un equilibrio de medidas y control, la decencia y generosidad en la vida cotidiana.

\section{(e) La separación de los reinos}

En este punto Novak se vuelve luterano y apela a la separación de los dos reinos, el del César y el de Dios, como doctrina cristiana fundamental. Asienta así la división Iglesia-Estado y el pluralismo socio-cultural. Algo que está en el fondo, dirá, del pluralismo estructural del capitalismo democrático. Y lo que es más importante, se sientan las bases para un sistema político social y económico de la libertad: libertad de mercado y libertad moral-cultural, de pensamiento y valores.

\section{(f) La caridad}

El amor caritativo es una concepción profundamente judeo-cristiana. Se funda en el Dios bíblico compasivo y liel. Cuando se pone esta doctrina en correlación con un sistema económico se nos plantea el problema de cómo "liberar la creatividad y la productividad humanas enfrentando de manera realista su pecaminosidad". Para ello la versión capitalista de la caritas cristiana hará hincapié en la productividad, el lucro, el activismo como la mejor forma de alcanzar "el ideal de la autonomía individual - respetar el bien del otro como tal-y un ideal de comunidad".

Quizá la intención "teologizadora" de M. Novak queda aclarada mediante una cita -que no necesita comentario- en que expresa su estilo y talante teológicos. Se trata, además, de una convicción que recorre la mente y el corazón de nuestro autor:

Durante muchos años uno de mis textos preferidos de la Escritura fue Isaías 53, 2-3: "Creció en su presencia como brote, como raíz en el páramo: no tenia presencia ni belleza que atrajera nuestras miradas ni aspecto que nos cautivara. Despreciado y evitado de la gente, un hombre hecho a sufrir, curLido en el dolor, al verlo se tapaban la cara; despreciado, lo tuvimos por nada". Quisiera aplicar estas palabras a la bussiness corporation modema, una encamación de la presencia de Dios en este mundo extremadamente 
despreciada". (M. Novak y J. W. Cooper (eds.), The Corporation: A Theological Inquiry, AEI: Washington , 1981, 203).

Ante esta cita es difícil sustraerse a la impresión de que en su ensayo teológico Noval ha estado sacralizando las instimciones americanas del capitalismo democrático e, incluso, "teologizando la política del mercado total" (F. Hinkelammert). Todo su pretendido correlacionismo no es más que un ejercicio de justificación, bajo el manto teológico, de aspectos del capitalismo, corno la competitividad, las multinacionales, etc. que resultan sorprendentes y escandalosos. Entre los rasgos llamativos y curiosos, por exóticos y burdos, hay una intención insistente para presentar la creatividad competitiva capitalista como el motor impulsor del "interés propio bien entendido" ${ }^{\text {"2 }}$, que producirá el bien común, la comunitariedad y hasta la solidaridad que alcanza la fraternidad

\subsection{Tres ideas bíblicas y el novus ordo capilalista}

Las tres ideas bíblicas, entre otras, que yacen tras el capitalismo democrático han sido sometidas durante largo tiempo, dira Novak, al método crítico racionalista del ensayo y el error en la sociedad americana ${ }^{73}$. Su éxito confirma su bondad. En el fondo estamos ante una repetición, vía biblica, de las ideas centrales ya seffaladas.

\section{(a) La noción cristiano-judia de pecado}

El neo-conservalismo acentúa esta condición pecadora del hombre. Funda aquí una desconfianza crítica en el hombre y sus realizaciones. Para Novak subyace a esta noción judco-cristiana la división de sistemas en la sociedad, la división de poderes dentro de cada sistema y una generalizada actitud que busca siempre comprobar lo que se afirma y equilibrar toda relación de poder. Incluso llegará a ver en esta tradición bíblico-republicana la desconfianza acerca del poder político sobre las instituciones económicas.

La tradición calvinista y republicana americana es quien mejor ha sacado las consecuencias político-sociales del dogma del pecado. Las "precauciones auxiliares" que se deben tomar frente a todo poder y gobemante, según Madison, señalan una tradición sensible al centralismo y al crecimiento de todo poder. "El lema será in God we trusi". Esto es, nobody else. "Los hombres son pecadores".

El realismo, la sobriedad, el rechazo de la utopía, la búsqueda de un meliorismo continuo, pero alcjado de ensueños, será familiar a esta tradición democrático capicalista.

\section{(b) El hombre imagen del Dios creador}

"El concepto judeo-cristiano, que se halla al comienzo del Génesis, acerca de la condición de inagen del Dios creador que tiene todo hombre, enseñó a los 
primeros americanos que la vocación de los cristianos, judfos y humanistas, no puede ser la de ser pasivos, resignados y reconciliados con la historia, sino, por el contrario, la de cambiar la historia, ser creadores, pioneros, y perseverar en la invención de un nuevo orden". Así sintetiza Novak ${ }^{74}$ una idea que cada vez ocupa un puesto más central en su intento de hacer "una teologia del capitalismo democrático".

En continuidad con A. Smith, verá una nueva moralidad que impregna al sistema económico que encame este espiritu de creatividad, inventiva y marcha hacia adelante. Estamos ante el auténtico "espíritu del capitalismo". Una concepción del mundo que termina, como decía A. Lincoln, "mejorando las condiciones de todos".

\section{(c) El hombre, individuo comunitario libre}

Es una idea distintiva también de la tradición judeo-cristiana. Está basada en la libertad, no en el nacimiento ni el color de la piel, el terribrio o la unidad religiosa Condujo en Norteamérica al asociacionismo voluntario que tanto le llamó la atención a Tocqueville.

Novak nos dirá que el sistema de mercado es una encarnación de este libre asociacionismo. Su práctica del "egoísmo ilustrado" se toma, a través del mecanismo del mercado, en atención al otro.

En un arrebato teológico-económico, Novak verá el impulso creativo hermanarse con esta orientación solidaria del mercado. El resultado serán millones de pequeños empresarios en la base de la actividad económica, que llamará "comunidades de base" ${ }^{m s}$, impulsando una actividad asociativa de millones de pequeñas asociaciones.

\section{Las funciones de la religión neo-conservadora}

El recorrido anterior nos permite preguntarnos, en una primera visión evaluadora de este tratamiento neo-conservador de la religión en el capitalismo democrático, cuáles pueden ser sus aportaciones y sus falacias.

\subsection{Las aportaciones neo-conservadoras al debate sobre la religión en la sociedad moderna}

No hay duda que - visto sobre todo desde Europa - en el haber de los neoconservadores hay que poner la revisión de la frecuentemente declarada inanidad de la religión en la sociedad modema secularizada. La tesis, simplificada, de la secularización y la privatización de la religión, dejó a menudo sin alcance socio-cultural el problema, vistu por Weber, del desencantamiento del mundo y la autonomía de las diversas esferas de valor. En esta situación, como hoy pone de manifiesto la polémica entre posımodernos y teóricos críticos (J. F. Lyotard y 
Habermas), se hace particularmente aguda la pregunta por "la unidad sociocultural" en la sociedad actual o "el modo de franquear los juegos de lenguaje hetereogéneos (la ciencia, la ética, la política)".

La propuesta neo-conservadora suena a recuperación tradicional e interesada de la religión. Pero la visión de Bell de que ni el control político ni la ingeniería social pueden sustituir a las tradiciones valorativas y morales de la sociedad, que tienen su fuente última en las concepciones religiosas que alienta una sociedad, merece ser examinada con cuidado. No se trata de volver a una unidad cosmovisional religiosa, sino de atender a una problemática compleja en la que se dan cita las cuestiones de la identidad colectiva, de la integración social y de la ética cívica. Desde Durkheim y sus representaciones colectivas, pasando por Weber hasta C. Castoriadis y su imaginario y la creación de significado sociohistórico, estas cuestiones limitan con la religión.

Tampoco está de más apuntar la llamada de atención que hacen acerca de las repercusiones ideológicas y socio políticas de las teologías o discursos sobre Dios. Preocupados por la política exterior norteamericana y por el miedo a la expansión comunista (y socialista), por su atención a América Latina, a la teología de la liberación y aún a la tcología política centroeuropea, estos autores distan mucho del ignorante olvido o la escasa atención que la izquierda europea (sobre todo espanola) dedica a la capacidad movilizadora de la religión. Claro está, que su preocupación llega a convertirse en problema de Eslado, como lo demuestra la Declaración de Santa Fe y, antes, el Informe Rockefeller sobre y contra los movimientos cristianos de liberación y su teología. Por esta vía se llega a un poder político que torna partido en cuestiones teológicas y a un Estado que se declara instancia de la ortodoxia religiosa.

\subsection{Funciones sociales de la religión neo-conservadora}

Resulta llamativa la importancia concedida por el neo-consevadurismo americano a la religión, tanto para explicar la crisis cultural del sistema, como para su superación. Pero la atención prestada resula sospechosa de manipulación interesada. El centro de sus preocupaciones lo ocupa la salud del sistema y, concretando más, la salud del funcionamiento de los subsistemas económicos (de libre mercado, según las propuestas neo-liberales de los Hayek y M. Friedmann que no desdicen ni Krisbl ni Novak), y de la democracia representativa con una administación pública descargada de las excesivas obligaciones adquiridas en la época expansionista del welfare state. La preocupación weberiana por el impacto socio-económico de la religión, a través de la configuración de un modo de ver el mundo y de comportarse en él, se transforma aquí en unilateral: interés por ver cómo se pueden aprovechar las potencialidades de una tradición (la judeo-cristiana) para recuperar aquella ética o sistema moral-cultural que estabilice y favorezca el desarrollo de un modo de concebir la sociedad (la demo- 
crático-capitalista). Del intento de explicación (Weber) hemos pasado a un intento de utilización terapético-social y legitimador.

Es un intento de utilización terapéutico-social de la religión cristiana, ya que, al funal, no hay consideración de la religión en sí misma, atendiendo a su propia logica, sino supeditación a una necesidad: superar la crisis.

Se trata de utilizar la religión (una nueva teologia económica, según Novak) para legitimar el capitalismo democrálico. La hipótesis de "afinidad electiva" entre capitalismo, democracia y cristianismo, está al servicio de una tarea ideológica doble: (1) contrarrestar la pretendida legitimación que el socialismo obtiene a través de las teologfas política y de la liberación y (2) obtener cтedibilidad y apoyo para el proyecto del neo-liberalismo capitalista.

No hay más que pensar que las declaradas "afinidades" entre capitalismo y cristianismo, que lleva a Novak hasta "las raíces evangélicas del capitalismo", pueden, en su generalidad y oferta de buenas intenciones, convenir perfectamente - y sin duda, mejor, como temen los mismos Novak y Kristol- al socialismo. Su énfasis en los logros históricos, sociales, de hecho, del capitalismo, para confirmar la tesis de su supremacía mediadora sobre el socialismo, son muy discutibles.

La pretendida recuperación social de las funciones de la religión termina, por la vía neo-conservadora, incurriendo nuevamente en un sometimiento funcional de la religión a las necesidades del sistema. Si la privatización de la religión, como vio Weber, reducía la religión a interiorismo y consuelo existencial del burgués (J. B. Metz), la religión con funciones sociales neo-conservadora responde al cambio de necesidades de la sociedad burguesa capitalista actual.

\section{Algunas cuestiones para la teología política neo-conservadora}

El intento neo-conservador suscita una serie de interrogantes y sospechas. Quisiera plantear las principales objeciones que, a mi juicio y al de otros críticos, presenta esta teología política neo-conservadora.

\subsection{Interpretación distorsionada del mismo capitalismo}

La primera reacción que produce la lecura de los logros y liberaciones del capitalismo según el neo-conservadurismo es de sorpresa e incredulidad. Sorpresa, porque nunca antes había leído tantos y diferentes éxitos aplicados exclusivamente al sistema capitalista. El que exista una interrelación entre la nueva ciencia moderna, por ejemplo, y el capitalismo, no quiere decir que se puedan hacer interpretaciones históricas tan masivas como las de Novak con la impresión de que estamos ante efectos producidos únicamente por el sistema capilalista. Cuando llegamos al caso de logros sociales, como la reducción de la jornada laboral, de las condiciones de trabajo, salario y otras mejoras sociales y 
de distribución más igualitaria, desconocer la importancia de las luchas sociales, del movimiento obrero y de los sindicatos y partidos políticos de izquierdas, es cegarse a la realidad histórica Pero si algo nos ensefla el neo-consevatismo es a ser conscientes del carácter interpretado y aún distorsionado, jamás desnudo, de los hechos histórico-sociales. Estamos ante una guerra ideológica. En esta refriega los neo-conservadores ni siquiera parecen dispuesios a conceder que, aunque "cl socialismo sea una idea muerta" (I. Kristol), sin embargo, sirvió para humanizar al capitalismo.

Hay que seguir el consejo de P. Berger y practicar "el are de la desconfianza" nielzscheana que ubica a los actores y sus ideas dentro de la sociedad y trata, en el mismo proceso, de descubrir sus interses creados.

\subsection{Aportaciones y ambigüedades}

Han sido varios los críticos que reconocen que los autores neo-conservadores tienen el mérito de plantear con realismo cuestiones que la teología política y la teología de la liberación no han abordado con claridad. Se trata del problema de las mediaciones: cómo hacer efectiva la opción por los pobres. Porque "no es el que dice ¡EI pobre, el pobre! el que entrará en el reino de los cielos, sino aquél que actualmente pone en acción un sistema económico que ayude al pobre a no serlo más'"n6. La cuestión, por tanto, no es de retớica, sino de análisis económico-político. Cómo incrementar la producción, distribuirla menos desigualmente y cómo hacerla compatible con el crecimiento de instituciones liores ${ }^{n}$. Hay que reconocer que la teología política y la de la liberación no han abordado ni contestado (quizá porque no está en sus manos) suficientemente a todo to que suponen estas cuestiones ${ }^{78}$. Hombres como J. L. Segundo son plenamente conscientes de este déficit de la teología de la liberación. Pero la solución "capitalista dernocrática" que, a menudo se quiere imponer en regiones como Centroamérica -de funestas consecuencias hasta el presente-, parece tener eco en el neo-conservatismo. A pesar de las evidencias en contra, están demasiado seguros de la bondad y éxito de "su" sistema.

Llama también poderosamente la atención que se rechace el llamado "socialismo democrático"7s. El temor a que el control del mercado degenere en centralismo y las ingerencias estatales se deslicen hacia el colectivismo, no son razones suficientes ni convincentes en un momento en el que no hay economía sin intervencionismo estatal y el libre mercado es un modelo que existe únicamente en los libros de texto. Sorprende la escasa crítica que recibe el mercado no controlado, la tendencia a la concentración de poder, etc.

Incluso el realismo del "siglo de la política económica socialdemócrala"so y las críticas al desarrollismo hechas por los nuevos movimientos sociales, no dejan de plantear una serie de peligros del capiralismo aun democrático. Asl, Berger y Benne reconocen que el capitalismo puede ser "rapaz y explotador" y 
sus beneficios pocas veces se reparterr confoimine al valor moral de los individuos que los reciben. Hay, asi mismo, una tendencia imperialista a "comercializar" la sociedad y la cultura. Estos aspectos no son sopesados a la hora de las alternativas. Parece que la ideologia (y tradición etnocéntrica) pesa definitivamente. La libertad se traga a la solidaridad, aunque los neo-conservadores pretendan equilibrar estos dos principios.

\subsection{Afirmaciones teológicas escandalosas}

Al intento de "una tcologia del capitalismo democrático", que tiene en Novak su máximo representante, hay que agradecer la claridad y rotundidad de su pretensión. Nos evita el andar con imputaciones: su objetivo, repetido como leit-motiv, es justificar teológicanente "el capitalismo democrático" frente a "la nueva clase" de "la cultura adversaria" presente en la teología política centroeuropea (Moltmann, Metz) y en la teología de la liberación.

Sin referimos de nuevo al uso peregrino de la interpretación que Novak hace de los principales dogmas cristianos en su obra más famosa y extendida $(E l$ Espíritu del capitalismo democrático, cap. 20), plantcaré algunas cuestiones a "las tres ideas biblicas" lundamentales donde ve justificado biblicamente el capitalismo democrático con su economía de mercado.

Lo menos que cabe decir es que, tanto la idea del pecado, de la imago Dei y de la comunilariedad del hombre, se pueden aplicar también - como vio Schumpeter - a las pretensiones del socialismo democrático. Realismo, control de los poderes, respelo de la libertad, valoración del urabajo creador y búsqueda de la solidaridad en la justicia, convienen más a los ideales socialistas que a los capitalistas. En principio no se ve cóno se puede deducir una aplicación exclusivista y acaparadora de cstas ideas bíblicas para un sistema específico, si no es tras las mediaciones de múluples interpretaciones, que, como hemos indicado, tienen más de opción ideológica que de análisis objetivo.

Hay momentos donde se advierten claramente tales mediaciones ideológicas. Por ejemplo, cuando M. Novak ve en el concepto del hombre imagen del Dios creador a traves de la creatividad competiliva una afinidad con las propuestas del capitalismo democrático"s. Novak transforma la competilividad en virtud teologal (caridad) y desde aqui, a través de "mediaciones realistas", en el único camino de respeto al otro y de fratemidad. Su énfasis en la base individual de la vida económica no llega a concordar, a pesar de sus esfuerzos, con la solidaridad acentuada por Laborem Exercens. Resulta una interpretación, al menos muy discutible, el que el mecanismo de mercado transforme el "egoísmo ilustrado" en comunitariedad y no en cooperativismo. Aquí sí que la desconfianza en la pecaminosidad del hombre se transmuta en confianza acrítica liberal en la estructura ${ }^{82}$. Uno sospecha que trata de encubrir uno de los puntos flacos del capitalismo $^{83}$. El canto a "la élica de la cooperación" capitalista, los origenes 
premodemos del individualismo occidental asociado posteriormente con el capitalismo (Berger), la concepción tradicional, emotiva y nostálgica de comunidad del catolicismo y del socialismont, tienen, sin duda, su punta de verdad; pero deducir el "individualismo comunitario" de la práctica económica del mercado y sus virtudes, es una simplificación ética y real. Sólo se puede entender como un intento para oblener esa solidaridad que, como ha visto D. Bell, constiwuye una necesidad para el funcionamiento justo de una sociedad y su legitimación. Pero que sea deducible del asociacionismo económico voluntario, es otro cantar. Nos hallamos ante un proceso de sacralización del mercado que trata de conferir plausibilidad humanizadora al capitalismo.

Para conseguir su objetivo justificador del capitalismo, Novak adopta la estrategia denigradora de sus contrarios. Hay un relativo avance, en los últimos escritos de este autor, respecto a su famosa obra El Espiritu del Capitalismo democrático. Ahora parece que sabe más y matiza más respecto a los teólogos de la liberación. Ensalza la espiritualidad de Gustavo Gutiêrrez y no es tan masiva la imputación marxista a la teología de la liberación, pero la estrategia descalificadora y de libelo se vuelve a utilizar a menudo. Asl, cuando se insiste en el marxismo, a menudo vulgar, de la teologla de la liberación's, su concepción histórica de la lucha de clases ${ }^{26}$, o de los pobres como detentadores de la verdad". Simplificaciones y estereotipos que son usados para reducir al contrario a la inanidad y mostrar lo peligroso de sus intereses. Estralegia de liquidación que Novak no ha ahorrado tampoco ante la carta pastoral de los obispos norteamericanos sobre asuntos económicos, a los que ha tachado, de hecho, de marxistas ${ }^{85}$.

Habria que devolverle a Novak algunas de sus frases brillantes y decirle: "demasiada 'teologia' y muy poco respeto hacia 'lo económico y político". Se da un exceso de "ética" y una comprensión excesivamente escasa de las irracionalidades del capitalismo democrático. Sorprende la ceguera neo-conservadora frente a las contradicciones económicas - no sólo culturales (D. Bell)del capitalismo y la deshumanización que producen. Un silencio que es una auténtica estrategia de enmascaramiento de la realidad.

\section{Actualidad del uso terapéutico-social de la religión neo-conservadora}

El intento neo-conservador de una teologla del capitalismo democrático hay que incluirlo dentro de un proyecto más amplio de lucha ideológica (P. Berger) para hacerse con las mentes de los americanos y de todo el mundo si fuera posible. "El corazón americano es conservador", dice un estudioso del neoconservatismo, P. Steinfels, pero ahora se trata de conquistar sus ideas. Sobre todo, de apoderarse de la tradición liberal. Como veremos, la ofensiva neoconservadora es toda una reconstrucción de la tradición liberal. Tiene como máximos enemigos a sus más próximos rivales: los socialistas democráticos. De 
ahr el interés por reducir su influencia donde vean un atisbo de sus ideas, incluidos los teólogos políticos y de la liberación. La teología política del capitalismo democrálico es su altemativa Tratan de asegurar así el control de uno de los elementos, el religioso, que sigue siendo influyente a la hora de motivar a los espiritus y de movilizar en pro o en contra de una forma de estructura social. Un proceso de legitimación en el que no se puede dejar de contar con la tradición judeo-cristiana.

En un momento histórico de inesperado triunfo mundial del capitalismo éste queda ahora enfrentado a sí mismo. Sus enemigos serán sus propios produclos y contradicciones: el saqueo de la biosfera, el crecimiento a ultranza, la destrucción de las zonas urbanas, el empobrecimiento y devastación del tercer mundo, el crash de la bolsa y las crisis financieras. Pero, todavia más, el capitalismo queda confrontado con lo que F. Fukuyama denomina "el tiempo triste" del fin de la historia: el profundo vacío de una sociedad privada de sentido moral y de utopía, como consecuencia de su carrera obsesiva por el éxito y el consumismo.

Para llenar este vacio y dotar de halo humanista al capitalismo pueden servir los usos terapéutico-sociales de la religión. Sospechamos que las legitimaciones religiosas neo-conservadoras van a ser necesarias y tendrán un gran campo de actuación a corto y mediano plazo. Quizá no al modo de la teologización ideológica de M. Novak, sino en versiones más suaves de los logros y realizaciones del sistema como hace P. Berger, haciendo desde ahí guiños a "las estructuras rcligiosas intermedias".

No se pueden olvidar, tampoco, los desafíos y cuestiones económicas que plantea el neo-conservatismo: la innegable eficacia productiva del sistema económico capitalista; la mayor elevación del nivel de vida material en algunos parses, en comparación con el llamado "socialismo real"; la eficacia del mercado corregido a través del intervencionismo estatal, frente a la "economía planificada"; el estancamiento e ineficacia de esta economia planificada una vez alcanzado cierto nivel...

¿Significa esto la supremacía indiscutible del sistema capitalista corregido por el intervencionismo estatal? ¿Nos movemos, por tanto, dentro del reformismo del sistema. pero no dentro su sustilución alternativa? ¿Es válida y generalizable esta preeminencia capitalista para los denominados paises del tercer mundo?

Graves cuestiones que afectan no sólo a los economistas y políicos, sino a loda persona responsable en el mundo de hoy.

El neo-conservatismo plantea la cuestión de la mediación económica más adecuada para resolver los problemas de pobreza, eficacia, bienestar, libertad. Su respuesta es clara: el mejor instrumento es la economía de mercado. Pero 
aunque fuese aceptada esta respuesta como válida, la cuestión es de límites y de acentos. Esta misma respuesta daria "la variante izquierdista del capitalismo democrático", el socialismo democráticos9. Hay pues, más cuestiones implicadas en el diagnóstico y propuestas neo-conservadoras.

\section{A modo de conclusión: la visión desde la periferia y la idolatría del sistema}

Cuando se considera la declarada opción neo-conservadora por los pobres desde la periferia del sistema - tercer mundo-, una sospecha loma cada vez más cuerpo: el centro del interés neo-conservador no son tanto las mayorías pobres cuanto el sistema mismo. Los neo-conservadores absolutizan su versión del capitalismo democrálico.

La intocabilidad de la lógica económico-política del sistema hace sospechar -como dice Habermas- que los límites del neo-conservalismo son los del sistema. Son ciegos para ver más allá. Su tratamiento de "los otros" está referido a las reacciones frente al sistema. No son vistos en sí mismos; no tienen nada que ofrecer; son sólo objeto de asimilación. Por eso, sus reticencias son consideradas peligrosas rebeldías para el sistema. Se establecen así relaciones puramente colonizadoras, impositivas, o de paternalismo imperialista. Los "otros" (pueblos, culturas, mayorías pobres...) son desconocidos en cuanto tal, porque su centro de atención y valoración es el sistema y sus estructuras. La mediación sistema- devora así a los destinatarios. Un peligroso culto idolátrico, en cuyo altar se puede sacrificar a los hombres que no se sometan al sistema.

La compasión no la despiertan los sujetos humanos, sino la estuclura. Se comprende ahora que $M$. Novack pueda sentir lástima por la business corporation y llegue a identificarla con el Siervo de Jahvé. Un absoluto desplazamiento - respecto a la teología de la liberación- sobre dónde se advierte el clamor de la presencia de Dios en este mundo. No sólo aparecen sensibilidades distintas, sino dónde se pone el corazón. El reino de Dios eslá para ellos más en una estructura que en los hombres. En definitiva, el reino queda subordinado a los imperativos de la estrucura capitalista.

Al final, nos asalta una pregunta: ¿qué tiene que ver este cristianismo neoconsevador con el de Jesús de Nazareth?

Nada, salvo unas cuantas referencias culturales. Se ha perdido la capacidad para ver dónde se revela el misterio del Dios de Jesús, dónde brota "la buena noticia"y dónde nace el gozo de su conocimiento. El Dios neo-conservador es un dios de ricos, privilegiados y capaces. Ciertamente -contra M. Novakofrece pocas afinidades con cl Dios bíblico. Más bien es su tergiversación, que se nos ofrece con la pretensión de suplantar al verdadero Dios. Una estrategia que continuará. Los neo-conservadores disponen para ello del triunfo mundial del sistema, pero carecen de la legitimidad del evangelio. 


\section{Notas}

1. S. Martin Lipseh "Neoconservatism: Myth and Reality", en Saciefy (julio-agosto, 1988) 29-37, 29.

2. Cfr. por ejemplo la atención prestada por los lécnicos críticos como I. Habermas, "Criticismo neo-conservador de la culaura en Estados Unidos y en Alemania Occidental", en: Habermas y la madernidad (R. Berstein, ed), Madrid, 1988; H. Dubiel, Was ist Neokonservarismus? Frankfurt, 1985; C. Offe, Parlidos políticos y nuevos movimientos sociales, Madrid, 1988.

3. Cfr. M. Novak, Will it liberate? Questions about Liberation Theology, N. Y., Mahwah, 1986, trad. cast. ¿En verdad liberaró?, México, 1988. Tesis central que recorre todo el libro desde sus primeras páginas. M. Novak es un americano nacido en Johnstown, Pennsylvania, de ascendencia eslovaca Fue aspirante a sacerdote católico, estudió teología en Roma (Gregoriana) y posteriomente historia y filosofía de la religión en Harvard. Ha sido profesor de las universidades de Stanford y Syracuse, e impartido cursos en Harvard y en la State University of New York Desde 1979 trabaja como investigador en el American Enterprise Instilue de Washington, sobre ternas de religión y política.

Otro autor, conservador, que participa del devocionismo capitalista, es G. Gilder, cuyos dos libros más importantes sobre el tema están traducidos: Riqueza y pobreza. Barcelona, 1987, y Espiritu de empresa, Madrid, 1989. Comentarios críticos sobre un tratamiento tan idcológico en: W. Kristol, "Los amigos y enemigos del capitalismo democrárico", en Fred E. Bauman (ed.) ¿Qué es el capilalismo democrárico?, Barcelona, 1988, 62-87.

4. Idem, El espíritu del capitalismo democrárico, Buenos Aires, 1984, 11; P. Berger, La revolución capitalista, Barcelona, 1989, 42s.; D. Bell, Las contradicciones culiurales del copitalismo, Madrid, 1977, 29.

5. Ibidem., 11; idem, Will ir Liberate?, 36; P. Berger, La revolución capifalista, 45s.

6. P. Berger, La revolución capitalista, 56.

7. M. Novak, Will is Liberase?, 36; Hacia el futuro, 75.

8. P. Betger, La revolución capisalista, 21-22.

9. Ibidem, 25.

10. M. Novak, El espirifu del capitalismo, 12; idem, Will it Liberate?, 38, 123-124; D. Bell, Las contradicciones, 23s; P. Berget, La revolución capialista, 22.

11. P. Berger, La revolución capilalista, 56; R. Benne, "Capitalism with Fewer Tears". en B. Grelle y D. A. Krueger, Christianity and Capiralism. Perspectives on Religion, Liberalism and the Economy, Chicago, 1986, 68.

12. Ibidem, 102s; R. Benne, Capilalism wish Fewer Tears, 70; Novak, El espirius del capisalismo.

13. Ibidem, 124s; Novak, Will is Liberate?, 119; R. Benne, Capisalism wish Fewer Tears, 69.

14. R. Benne, Capisalism with Fewer Tears, 71; D. Bell, Las consradicciones, 88.

15. Ibidem. 71s; Novak, El espírity del capisalismo; idem; Will it Liberale?, 75s; L. Belúán, Cristianismo y economía de mercado, Madrid, 1986, 20.

16. Shumpeter, Capitalismo, sacialismo y demacracia, Barcelona, 1984, $118 \mathrm{~s}$.

17. M. Novak, Will is Liberale?, 77, 86. 
18. Idem, El espiriut del capitalismo, 47s.

19. Idem, Will is Liberate?, 846; R. Berme, Cepisalism wish Fewer Tears, 73; D. Bell, Las contradicciones, 188; P. Berger, La revolución capitalista, 105s.

20. P. Berger, La revolución capisalista, 101.

21. Ibidem, 96.

22. Novik, Will is Liberate?, 61-62; Benne, Capitalism wish Fewer Tears, 67.

23. Idem, El espirisu del capisalismo; idem, Will it Liberare?; R. Berme, Capisalism with Fewer Tears, $74 s$.

24. Berger, La revolución capisalista, 56s; R. Benne, Capitalism with Fewer Tears, 72.

25. Jbidem, 186.

26. Novak, Will is Liberase?, 77.

27. Ibidem, 186.

28. Ibidem, 3.

29. Ibidem, 6; P. Berger, La revolución capisalista, 262; Hacia el fuuro, 76.

30. Ibidem, 30.

31. Ibidem, 5.

32. Ibidem, 30.

33. Ibidem, 8.9s.

34. Ibidem, 34.

35. Ibidem, 5, 26, 31, ...; Berger, La revolución capiralista, $262 \mathrm{~s}$.

36. Ibidem, 5 .

37. S. Lipset Neoconservatism: Myth and Realiry, 31.

38. Novak, Will is Liberate?, 23, 24, 134.

39. Podhoretz, Los nuevos defensores del capitalismo. Perspectivas económicas, 36 (1981) 59-63; J. Muller, "Capitalism: The Wawe of the Future", Commentary 6 (1989), 21-26. Tras el desmantelamiento del Bloque del Este el sentimiento de triunfo del capitalismo se ha generalizado. Visión crítica matizada: Dissent (Spring 1990), Revolution in Europe. Es interesante notar como el capitalismo se presenta como realismo o pragmatismo enfrentado a la utopra. Pero de esta anti-utopía se desprenden consecuencias utópicas. Es el camino para la realización de la sociedad perfects.

40. Berger, La revolución capisalista, 235 s.

41. I. Kristol, Reflections, 317.

42. P. Berger, La revolución capitalista, 236.

43. Podhoretz, Los nuevos defensores del capitalismo, 62.

44. Novak, Will it Liberate?, 9.

45. Idem, El espíriru del capiralismo, 11.

46. Ibidem, $357 \mathrm{~s}$.

47. M. Weber, La ética prolestanse, 93, 107.

48. M. Novak, El espíriu del capitalismo, 69s. Novak tiene suficiente formación teológica y sutilidad democrático-pluralista para no tratar de hacer una "sociedad cristiana". Pero su tratamiento de la búsqueda de congruencias y afinidad no deja de ser un modo para utilizar la religión en favor del sistema.

49. Ibidem, 71; idem, Versión renovada de la sociedad democrática (VRSD), 44 45.Sobre este aspecto habría que tent en cuenth, para situar el análisis neo-con- 
servador, que hablan desde Estados Unidos, donde: (1) según Gallup el 69\% de los norteamericanos son miembros de alguna Iglesia y el $40 \%$ asisten a los servicios religiosos semanales cfr. Religion in America, Princenton, 1981, 4-5; (2) la gran influencia que se le reconoce a la religión en la vida política americana al ser las iglesias los centros de activismo, cfr., S. Martin Lipset, Religion in America Politics, en M. Novak (ed.), Capitalism and Socialism, 61-85. También Nomn Chomsky, "La enfermedad de la democracia americana", El Pals 29-XI-86; Novak, VRSD, 62 sintetizaré esta situación diciendo: "Estados Unidos es quiź́ el país más religioso, en su práctica y en sus actibudes explicitas, del mundo moderno", cfr. también Greeley. Religions change in America, Cambridge, Mr-Londres, 1989.

50. Ibidem, 71-72.

51. A tútulo ejemplar recordemos entre los teslogos a J. B. Metz, J. Moltmann y Josua; entre los sociólogos de la religión habria que poner junto P. Berger y T. Luckmann a B. Wilson, R. Bellah y Glock.

52. Novak, El espiritu del capiralismo, 72; VRSD, 45.

53. Idem, VRSD, 64, 71; I. Kristol, Reflexiones, 57.

54. Ibidem, 65.

55. Ibidem, 66.

56. Ibidem, 66-67.

57. Ibidem, 68; Kristol, Reflexiones, 176.

58. Ibidem, 68.

59. Ibidem, El espirifu del capisalismo, 73s.

60. Ibidem, 69; El esplritu del capitalismo, 77.

61. Ibidem, 69; El esplritu del capitalismo, 74; Kristol, Reflections, 80s; idem, The Spiritual Roots of capitalism and socialism, en M. Novak (cd.), Capitalism and sacialism, 2s.

62. Ibidem, 70; El espórisu del capitalismo, 85s.

63. Idem, El espiritu del copisalismo, 87.

64. Ibidem, 89.

65. Ibidem, 92.

66. Ibidem, 257s; Kristol, The Spiritual Roots, 8.

67. Ibidem, 259.

68. Ibidem, cap. 15 y 17 y Will it Liberate?

69. Ibidem, cap. 19, pag. 337s.

70. Ibidem, 360. En lo que sigue tendremos en cuenta el cap. 20 de El espírisu del capilalismo democrático.

71. Idem, Free Persons and Common Good, 73 donde insiste en ideas parecidas.

72. Concepto que Novak y los neo-conservadores toman de A. Tocqueville, Demacracia en América, Madrid, 1980, vol. 2, 109. Cfr. el puesto que tiene este concepto en Hacia el furwo, 24; M. Novak, Free Persons and The Common Good, Lenhem-N. Y.-Londres, 55s. Críticamente H. Assmann; F. J. Hinkelammert, A idolatria do Mercado. Ensaio sobre Economía e teologla,Sao Paulo, 1989, 44s.; F. J. Hinkelammerh Demacracia y totalitarismo, San José (Costa Rica) 1987, 180s, 229s.

73. Novak, Will is Liberate?, 69.

74. Ibidem, 40; Hacia el futuro, 27s; idem, Free Persons.

75. Ibidem, 80. 
76. Ibidem, 125; Hacia el Futro, 69.

77. Pawlikowshi, "Modern Catholic Teaching on the Economy: An Aralysis and Evaluation", en B. Grelle; D. A. Krleger. Christianity and Capisalism, 23; I. B. Cobb, Christianity, Political Theology and the Econoric Fuwe, 209s.

78. Véase, el esfuetzo de H. Assmann y F. J. Hinkelammerth $A$ idolatria do Mercado, o. c. para abordar las cuestiones económicas desde la teologia de la liberación. Con codo, se puede, sin menospreciar el esfuerzo, dudar que la problemática económica esté resuelis.

79. Novak, El espíriru del capitalismo, 369; Will it Liberate?; Podhoretz, Los nuevos defensores del capisalismo, 61. Críticamente: M. Harrington, Socialism: Past \& Future, N. Y. 1989; R. Dahl; "Free Markets. Social Realily \& Free Markets", Dissent, Spring 1990), 224-228.

80. R. Dahrendorf, "Al final del siglo socialdemócrata", en idem, La oportunidad de las casas, Madrid 1983, $14 s$.

81. Novak, El espfritu del capiralismo, 185s; Hacia el fuluro, 27s.

82. I. Calvez, "Capitalisme democratique?", Choisir, 329 (mai 1987) 23-25, 25.

83. I. Camacho, "El capitalismo y la justicia inlemacional", Revista de Fomento Sacial, 73 (1989) 21-24-43; 42; A. Guillén, "Los valores de la economía de mercado. Las tesis de M. Novak", Revista de fomento social, 73 (1989) 7-21.

84. Novak, El espíritu del capitalismo, 135, 144s; idem, Freedom with Justice, Harper/ Row, S. Francisco, 1984, 495s.

85. Idem, Will it Liberale?, 27s; 148-149s.

86. Ibidem, 151-152.

87. Ibidem, 148.

88. Novak, "McGovernism Among the Bishops". Washington Times 25 de octubre de 1985; cfr. D. Hollenbach, "Justice as Participation: Public Moral Discourse and the U. S. Economy", en Ch. H. Reynolds/R. V. Norman, Community in America. The Challange of Habits of the Heart, Berkeley-Los Angeles-Londres, 1988, 217-230, 218; J. Hitchcock, "The Catholic Bishops, Public Policy and the New Class", en This World, 9 (1984) 54-56.

89. M. Novak, El esptrisu del capisalismo, 358. 